\title{
Short communications on miscellaneous subjects
}

\section{PHYSICAL PROPERTIES OF CERVICAL MUCUS IN RELATION TO BOVINE FERTILITY}

\author{
G. W. SCOTT BLAIR \\ Physics Department, National Institute for Research in Dairying, \\ University of Reading, England
}

SUMMARY

Flow (rheological) properties, and the intensity of a band in the ultra-violet absorption spectra of cervical mucus, change in a meaningful and regular manner during the bovine oestrous cycle and also in early pregnancy. Their study has led to field-tests for oestrus and pregnancy in normal animals. These changes in physical properties are related to the balance of oestrogen and progesterone and are, therefore, also affected by certain pathological and subfertile conditions. Infra-red absorption and flow-birefringence of the secretions are also being measured.

Flow properties in relation to "heat" and PREgnancy

It has long been known that the rheological properties of the mucus secreted within the uterine cervix of the cow (and other species) change in a regular manner during the oestrous cycle and in early pregnancy. For a historical survey see a chapter by the present author in a book by FREY-WYssLing (1952).

\section{a Oestrus}

As a practical application, Scott Blair, Folley, Malpress and Coppen (1941a) described an instrument called an "oestroscope" which measures the recoil when pressure is suddenly withdrawn during the extrusion of a column of secretion out of a narrow glass tube ("Flow-elasticity"). A modern form of the oestroscope is shown in Fig. 1. (By permission of the Editor of Agriculture 62 (1955) 17 and of the Controller of H.M.S. Stationary Office).

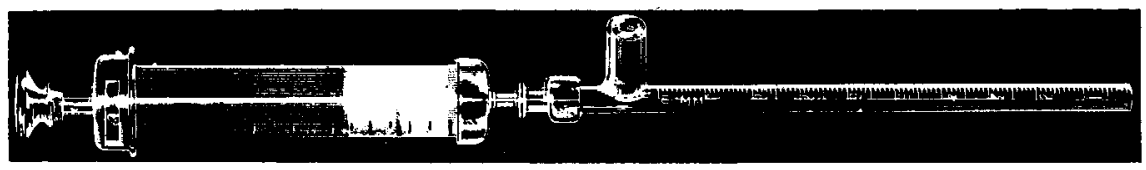

Fig. 1. THE OESTKOSCope.

Flow-elasticity is negligible at all times except during or very near oestrus. Herman and Horton (1948) and RAps (1949) claim that maximum flow-elasticity occurs just at the onset of "heat", some 6-12 hours before the optimum condition for penetrability of sperm. The test is therefore useful to those concerned with Artificial Insemination.

\section{$b$ Pregnancy}

After some years of preliminary work, ScotT BlaIR and GLower (1955) have shown that, for normal cows, the uverall consistency of the cervical mucus calculated from the rate of extrusion from a narrow glass tube under constant 


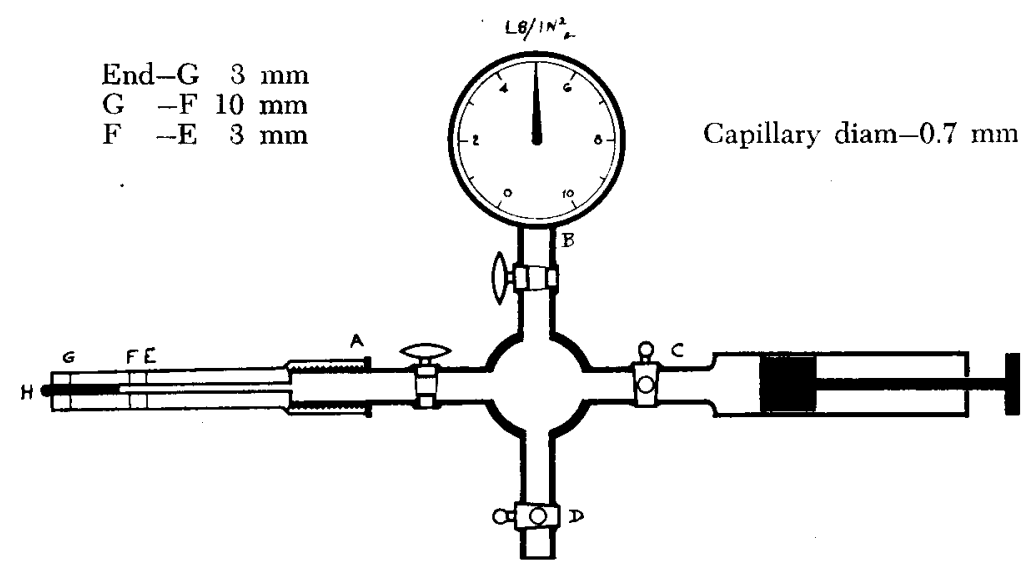

Apparatus for measurement of overall consistency of cervical mucus.

Fig. 2. The CONSISTOMETER.

(air) pressure, is greater in pregnant than in non-pregnant animals. Pregnancy can be diagnosed by this means with over $90 \%$ accuracy at about 5 weeks, preliminary tests at 4 weeks giving $77 \%$ correct results. The consistometer used for these tests is shown in Fig. 2. (By permission of the Editor of Brit. Vet. J.).

\section{ULTRA-VIOLET ABSORPTION SPECTRA}

Following preliminary work by Glover (1953), Scott Blair and Glover (1955) showed that if the secretions are dispersed in water to the same concentration $(0.14 \%)$, the $\mathrm{u}-\mathrm{v}$ absorption (per unit concentration and length) at $278 \mathrm{~m} \mu$ is greatest in pregnancy, and smaller in dioestrus. There is hardly any peak in the absorption curve at oestrus. In the later experiments, a technique was used by which the rather lengthy dispersion process is eliminated, undiluted samples being used. The average absorption per unit length for 23 pregnant cows was $5.3 \mathrm{~cm}^{-1}$, for 15 dioestrous cows, 2.1 and for 7 in oestrus, 0.2 . This absorption band is almost certainly due to proteins and it is known that the nitrogen content of the secretions is much lower at oestrus than in dioestrus (Scott Blair, Folley, Malpress and Coppen (1941 b)).

\section{Physical properties in RELATION to hormonal LEVElS}

The above experiments suggest that a flow-elasticity and a generally low consistency are associated with a preponderance of oestrogen over progesterone in the blood; and that a high consistency and the presence of substantial amounts of certain amino-acid groups are linked with higher progesterone levels. This hypothesis has been strengthened by a few experiments on ovariectomized cows. When treated with oestrogen, secretions are produced showing flow-elasticity, low consistency and virtually no absorption band at $278 \mathrm{~m} \mu$, whereas the addition of progesterone produces samples with properties like those of dioestrous or, with larger doses, pregnant animals. There is no secretion with progesterone alone.

This linking of physical properties with hormone levels reveals both the advantages and disadvantages of the use of these properties for diagnostic purposes. 


\section{Pathological and subfertile conditions : SAMPling techniques}

First, the hypothesis leads one to expect that any unusual or pathological hormonal condition may lead to the risk of a false diagnosis. This is verified in many respects. A fairly common type of subfertility, leading to the need for repeated inseminations, is associated with a tough, pregnant-type of secretion (except at oestrus) and indicates too low an oestrogen-progesterone ratio. The non-pregnant level of dioestrous consistency must be known for such animals if false pregnancy diagnoses are to be avoided. Probably less common is subfertility associated with a "runny" secretion at dioestrus and even in early pregnancy. It is clear that such conditions as a retained corpus luteum, will be likely to produce a more "pregnant" type of secretion and that a cervical erosion, for example, by diluting the secretion, may, if undiagnosed, lead to a failure to detect pregnancy. About $5 \%$ of cows in a recent experiment were found to be pathological enough to give misleading diagnoses, at any rate if no special allowance was made for their individual conditions.

Flow-elasticity is such a striking phenomenon and the secretion is generally so copious at oestrus, that any sample from the vagina can be used for the oestroscope. But for pregnancy tests, it is most important that the sample, which is often very small, should be taken with considerable care, using a speculum, directly from the os of the cervix. On the average about $0.1 \mathrm{ml}$. of sample is available; but the consistometer only requires $0.006 \mathrm{ml}$. for each run. Since homogeneity of samples is not good, it is best to take an average of several runs. (For details see Scott Blair and Glover (1955)).

COMPOSITION AND SIZE OF MUCIN MOLECULES

GLover (1953) has shown, in a few preliminary experiments, that there may well be characteristic differences in the flow-birefringence of secretions from cows in oestrus, dioestrus and pregnancy. Suitable apparatus has now been constructed and further experiments are in progress. It is hoped that these will help to disclose something of the size of the molecules responsible for the phenomena which have been observed. Extremely little is known about the chemical composition of the secretions, earlier investigations having proved to be extremely difficult. It is hoped soon to pursue a biochemical approach and also, Dr. J. D. S. Goulden at the N.I.R.D., Reading, is already examining absorption spectra in the infra-red region.

\section{Conclusions}

Apart from tests for oestrus and pregnancy already developed, the association of physical and chemical properties of cervical secretions with hormonal levels suggests that these properties may throw light on the all too common cases of bovine subfertility, known to be related to hormonal imbalance.

\section{ACKNOWLEDGEMENT}

My best thanks are due to my colleague, Mr. F. A. GLover, for helpful comments.

\section{ReFERENCES}

Frey-Wyssling, A.: Problems of Flow in Biology, Amsterdam, 1952.

Glover, F. A. : Ultra-violet absorption spectra and flow-birefringence of bovine cervical secretions. Nature (London) 172 (1953) 255. 
Herman, H. A. and O. H. Honton: Spermatozoa behavior in cervical mucus at varying stages of oestrus. J. Dairy Sci. 31 (1948) 679-680.

Raps, G. R.: The role of the veterinarian in an artificial insemination program. $J$ Amer. Vet. Med. Assocn. 114 (1949) 206-210.

Scott Blair, G. W., S. J. Folley, F. H. Malpress and F. M. V. Coppen: (a) The oestroscope : an instrument for detecting oestrus in cows. Vet. Record. 53 (1941) 693-695; (b) Variations in certain properties of bovine cervical mucus during the oestrous cycle. Biochem. J. 35 (1941) 1039-1049.

.. - and F. A. GLover: Early pregnancy tests from studies of bovine cervical mucus. Brit. Vet. J. 111 (1955) 3-11.

\title{
HEAT TRANSFER TO BOILING SKIMMILK
}

\author{
S. J. D. VAN STRALEN \\ Laboratory of Physics and Meteorology, Agricultural University, \\ Wageningen, Netherlands
}

\begin{abstract}
SUMmary
The heat flux to boiling pasteurized skimmilk was determined by using a horizontal platinum heating wire, which served at the same time as a resistance thermometer.

A gradually increasing coagulation layer was precipitated on the wire at a constant heat flux of $10 \mathrm{cal} \mathrm{sec}^{-1} \mathrm{~cm}^{-2}$ under atmospheric pressure, which was attended by a rapid decrease in the coefficient of heat transfer.

The heat flux to skimmilk under a pressure of $10 \mathrm{~cm} \mathrm{Hg}$ exceeded considerably that to water at the same temperature of the wire, and a higher maximum of nucleate boiling was found. Solutions containing small amounts of skimmilk in water showed similar high maxima.
\end{abstract}

\section{Method AND apparatus}

The rate of heat flow $q$ from a heated wire to a boiling liquid is a function of $\Theta=t-T$, the difference in temperature between the heating surface and the bulk liquid. The curves representing the heat flux $\frac{q(\Theta)}{A}$, where $A$ denotes the area of the heating surface, consist of three parts : the region of convection, in which no vapour bubbles are observed, the region of nucleate boiling, in which vapour bubbles are generated on special spots of the surface, and the region of filmboiling, in which a gradually increasing area of the surface is covered with a coherent layer of vapour. In the regions of convection and nucleate boiling the values of $\Theta$ are small or moderate, in contradistinction to the region of filmboiling, where $\Theta$ amounts to much higher values (v. WIJK, Vos and v. Stralen, 1956).

The method described by McAdams (1948) has in principle been used to determine the heat transfer curves up to the maximum of nucleate boiling for pasteurized skimmilk, for water and for solutions containing small amounts of skimmilk in water, all at a pressure of $10 \mathrm{~cm} \mathrm{Hg}$. For that purpose a gradually increasing D.C. was passed through a horizontal platinum wire, of which a central portion was isolated as a test section by the use of thin potential taps. This section served as a heating surface and at the same time as a resistance thermometer. The heat flux and the temperature difference 